\title{
Effects of Moisture and Salinity on Methane Adsorption in Kerogen: A Molecular Simulation Study
}

\author{
Juan Zhou, ${ }^{\dagger}$ Qian Mao, ${ }^{\dagger}$ and Kai H. Luo*, ${ }^{\dagger, \ddagger}$ \\ ${ }^{\dagger}$ Center for Combustion Energy, Key Laboratory for Thermal Science and Power Engineering of Ministry of Education, Department \\ of Energy and Power Engineering, Tsinghua University, Beijing 100084, People's Republic of China \\ ${ }^{\ddagger}$ Department of Mechanical Engineering, University College London, Torrington Place, London WC1E 7JE, United Kingdom
}

Supporting Information

\begin{abstract}
The adsorption characteristics of methane in shales play a critical role in the assessment of shale gas resources. The microscopic adsorption mechanism of methane considering the effect of moisture and especially salinity remains to be explored. In this work, combined molecular dynamics and grand canonical Monte Carlo simulations are conducted to investigate the adsorption behaviors of methane in the realistic kerogen matrixes containing different moisture contents $(0-6 \mathrm{wt}$ $\%)$ and various salinities $(0-6 \mathrm{~mol} / \mathrm{L} \mathrm{NaCl})$. Adsorption processes are simulated under realistic reservoir conditions at four temperatures in the range from 298.15 to $358.15 \mathrm{~K}$ and pressures up to $40 \mathrm{MPa}$. Effects of the moisture content on methane adsorption capacities are analyzed in detail. Simulation results show that the methane adsorption capacity declines as the moisture content increases. In comparison to the dry kerogen matrix, the reduction in the maximum $\mathrm{CH}_{4}$ adsorption capacity is as high as $42.5 \%$ in moist kerogen, with a moisture content of $6.0 \mathrm{wt} \%$ at $338.15 \mathrm{~K}$. The overlap observed in the density distributions of water molecules and decrease in adsorbed methane indicates that the water molecules occupy the adsorption sites and, thus, lead to the reduction in methane adsorption capacity. Besides, the effects of salinity on $\mathrm{CH}_{4}$ adsorption isotherms are discussed. The salinity is found to have a negative influence on the methane adsorption capacity. The maximum $\mathrm{CH}_{4}$ adsorption capacity reduces around $6.0 \%$ under the salinity of $6 \mathrm{~mol} / \mathrm{L}$ at $338.15 \mathrm{~K}$. Adsorption of methane in kerogens of constant salinity but different moisture contents are further discussed. Results from the present study show that the moisture content has a greater impact on the adsorption of methane compared to that of salinity. The findings of this study have important implications for more accurate estimation of shale gas in place.
\end{abstract}

\section{INTRODUCTION}

Natural gas, particularly shale gas, is identified as a relatively clean energy source that helps reduce greenhouse gas emissions. Shale gas has recently attracted considerable attention because many countries have proven to have large shale gas deposits, which may offer the opportunity to reduce their reliance on energy imports. ${ }^{1,2}$ In 2017, the U.S. Energy Information Administration (EIA) reported that the dry natural gas production in the United States was slightly greater than natural gas consumption, in which shale gas wells served as the largest source of total natural gas production, providing $57 \%$ of total natural gas production. ${ }^{3}$ Thus, plenty of efforts are being devoted to the storage evaluation ${ }^{4}$ and exploitation of the shale gas resources. ${ }^{2}$

Shale gas is predominantly methane and mainly reserved in the shale formation. Shale is dense, with pores in the range of nanometers and permeability in the range of nanodarcies. Shale formations consist of two parts: inorganic and organic. The inorganic minerals are mostly made of clay, silica, calcites, etc. Kerogen makes up the predominant component of the organic matter in most shales ${ }^{5}$ and is considered as a most favorable place for the occurrence of shale gas. ${ }^{6}$ Generally, there are three modes of shale gas occurrence in reservoirs, including adsorbed gas, free gas, and dissolved gas, among which adsorbed gas (up to $85 \%$ ) and free gas are the main shale gas modes of occurrence. ${ }^{7}$ Understanding the methane storage, especially the adsorption mechanism in kerogen, is important for the accurate assessment of the storage potential and the effective design for exploitation of shale gas.

The organic matter in shales is generally considered to be hydrocarbon-wetting in shales. ${ }^{8}$ However, the existence of water in kerogen materials is proven in several recent studies. $^{9-11}$ Kerogen from the Lower and Middle Cambrian deposits of the Kuonamka Formation were reported to have moisture contents in the range of $0.6-5 \%$. $^{9}$ Kerogen exhibits a mixed-wet characteristic because the carbon skeleton is hydrophobic, whereas the oxygen functional groups are hydrophilic. The higher proportion of hydrophilic to hydrophobic sorption sites increases the moisture content and, consequently, decreases the adsorption capacity of methane. ${ }^{10}$ Several experimental studies have investigated the relationship between the water content and $\mathrm{CH}_{4}$ adsorption capacity in shales. It is found that the presence of moisture can lead to a sharp decline in the methane adsorption capacity based on the hypothesis that the occupation of moisture in surface sites or pore throats would reduce the effective pore volume and block the access of methane to adsorption sites. ${ }^{4,12-14}$ Most of the experimental research focuses on adsorption in shale samples, but the existence of clay minerals in the shale samples would influence the methane adsorption properties because the

Received: February 6, 2019

Revised: $\quad$ March 27, 2019

Published: April 30, 2019 
presence of water has more significant effects on clay minerals than organic matter as a result of their difference in wettability. ${ }^{15}$ It is not easy to isolate kerogen from shale samples and keep the morphology of kerogen intact in experiments. ${ }^{5}$ Moreover, there exists a large percentage of nanosized pores in organic kerogen material, while experimental studies on exploring pore volumes at the nanoscale and microscopic properties of fluids remain challenging.

Molecular simulations provide insights into the adsorption phenomena and properties at the atomic scale and allow for the control of the microstructure. Besides, simulations are access to high-pressure and high-temperature conditions that are difficult to achieve in the experiment. Molecular simulations have been applied widely to the prediction of thermodynamic properties of adsorbed fluids in microporous media over the past few decades. ${ }^{16-23}$ In these research, the planar graphene slit pore model ${ }^{16,17,24}$ and graphite model modified with functional groups ${ }^{18-22}$ are adopted to simplify the nanoporous organic materials in shales. With the modification of the oxygenated group, the carbonyl $(-\mathrm{C}=$ $\mathrm{O})$ group used here, onto the graphene surfaces, $\mathrm{Hu}$ et $\mathrm{al}^{18}$ revealed that, for shales of higher $\mathrm{O} / \mathrm{C}$ ratios, kerogen may be mixed-wet or even hydrophilic. Liu and Wilcox ${ }^{22}$ analyzed adsorption of $\mathrm{CH}_{4}, \mathrm{CO}_{2}$, and $\mathrm{N}_{2}$ gas mixtures in functionalized graphitic slit pores and reported that the surface chemistry influences the adsorption selectivity of gas mixtures in carbonbased sorbents. Results of these studies imply that the heterogeneity of kerogen is critical and should be taken into account and the smooth graphene slit-pore model may not have the ability to describe the realistic kerogen structures with complex pore surface roughness and surface-functionalized chemistry. Therefore, more realistic kerogen models have recently been used to capture the adsorption properties in shales, which are highly heterogeneous. Zhao et al. ${ }^{25,26}$ examined the influence of the moisture content on methane adsorption on a type II kerogen model under pressures up to $20 \mathrm{MPa}$ using grand canonical Monte Carlo (GCMC) simulations and found that the amount of methane adsorption drops sharply in the presence of moisture. They also pointed out that the moisture content has a greater effect on methane adsorption in mature kerogen than that in immature kerogen. More recently, Huang et al. ${ }^{27,28}$ also performed GCMC simulations to study the methane adsorption in kerogens with the existence of water and reported that the increasing moisture content results in a decrease of the effective pore volumes and, thus, leads to the reduction in adsorption capacities. Despite the important findings gained in these studies, the microscopic mechanism of the water effect on methane adsorption in kerogen was not thoroughly understood.

Moreover, previous studies were only restricted to the effects of water contents on $\mathrm{CH}_{4}$ adsorption, and pure water was employed as a substitute for underground water in kerogens. However, produced water generated during shale oil and gas production is highly saline and possesses a much higher salinity than injection water. ${ }^{29-31}$ The salinity of subsurface water commonly increases with depth below the surface. ${ }^{29,32}$ Among the chemical compositions in the saline water, the dominant anion is generally $\mathrm{Cl}^{-}$and $\mathrm{Na}^{+}$is the dominant cation in chloride waters. $^{32}$ However, very little is known about the effects of salinity on methane adsorption properties in shales.

In this study, realistic kerogen matrixes are constructed using molecular dynamics (MD) simulations, with the representative functional groups incorporated to represent the shale organic pore structure. On the basis of the kerogen matrixes, GCMC simulations are carried out to investigate the methane adsorption properties in kerogens of different moisture contents and salinities at four different temperatures under pressures up to $40 \mathrm{MPa}$. To figure out the effects of the water content on the methane adsorption, the distributions of water and methane molecules in the kerogen matrix are quantified and visualized. In terms of salinity effect on methane adsorption, sodium chloride aqueous solution is chosen to represent the saline water in kerogen for its ubiquity in shales. The purpose of this work is to gain an understanding of the effects of moisture and salinity on methane adsorption in kerogen and further offer some important insights into the accurate prediction of shale gas storage as well as effective shale gas recovery.

\section{METHODOLOGY}

2.1. Kerogen Model. Among the three types of kerogen, type II kerogen is commonly deposited in marine environments and has relatively high $\mathrm{H} / \mathrm{C}$ and low $\mathrm{O} / \mathrm{C}$ ratios. ${ }^{33}$ Our investigation focuses on the methane adsorption in type II kerogen, which is particularly frequent in many petroleum source rocks and oil shales. ${ }^{34}$ The kerogen molecular unit (type II-C) used in this study was proposed by Ungerer et $\mathrm{al}^{35}$ on the basis of experimental data published by Kelemen et al. ${ }^{36}$ The chemical formula of the type II-C kerogen macromolecule is $\mathrm{C}_{242} \mathrm{H}_{219} \mathrm{O}_{13} \mathrm{~N}_{5} \mathrm{~S}_{2}$, and its molecular weight is $3469.9 \mathrm{~g} / \mathrm{mol}$. The structure of the model unit is illustrated in Figure 1.

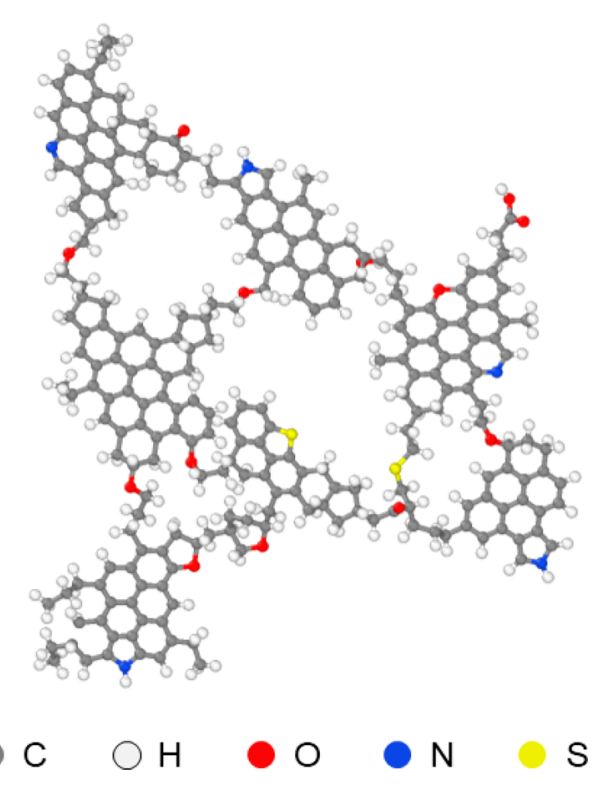

Figure 1. Molecular model of type II kerogen. The chemical formula is $\mathrm{C}_{242} \mathrm{H}_{219} \mathrm{O}_{13} \mathrm{~N}_{5} \mathrm{~S}_{2}$. Atom representation: gray for carbon atoms, white for hydrogen atoms, red for oxygen atoms, blue for nitrogen atoms, and yellow for sulfur atoms.

2.2. Molecular Models. Details of the molecular models adopted in the current study are depicted in this section. Discussions on the molecular structures, the intra- and intermolecular interactions of the type II kerogen matrix, methane, water, helium, and sodium chloride are included.

2.2.1. Kerogen Matrix Generation. A series of MD simulations were performed in the canonical ensemble $(N V T)$ and isobaric isothermal ensemble (NPT) to generate the condensed kerogen matrix. For the kerogen model, the Dreiding force field, ${ }^{37}$ which is 
proven to show good performance in predicting structures and dynamics of organic molecules, ${ }^{38}$ was employed. Before the construction of the condensed kerogen matrix, the initial structure of the kerogen molecular unit was relaxed individually. Then, eight relaxed kerogen units were randomly placed in a cubic simulation box with dimensions of $10 \times 10 \times 10 \mathrm{~nm}^{3}$, in which the initial density of kerogen is approximately $0.05 \mathrm{~g} / \mathrm{cm}^{3}$. According to the relaxation procedures applied in the previous studies, ${ }^{25,35,39}$ the initial configuration should be relaxed in successive MD simulations from high temperatures to typical reservoir conditions. Therefore, MD simulations were conducted in the NVT ensemble at $1000 \mathrm{~K}$, and after that, the system was relaxed step by step in the NPT ensemble at $200 \mathrm{~atm}$ through a stepwise decreasing temperature $(900,700,500$, and $300 \mathrm{~K}$ ). Each run duration was set as $200 \mathrm{ps}$ to make sure that the kerogen density converged to the equilibrium value. At last, a $\mathrm{MD}$ simulation in the NPT ensemble at $338 \mathrm{~K}$ and $200 \mathrm{~atm}$ was performed for $1 \mathrm{~ns}$ to obtain a stable kerogen structure. The final configuration of the kerogen matrix is presented in Figure 2. The microstructure of this

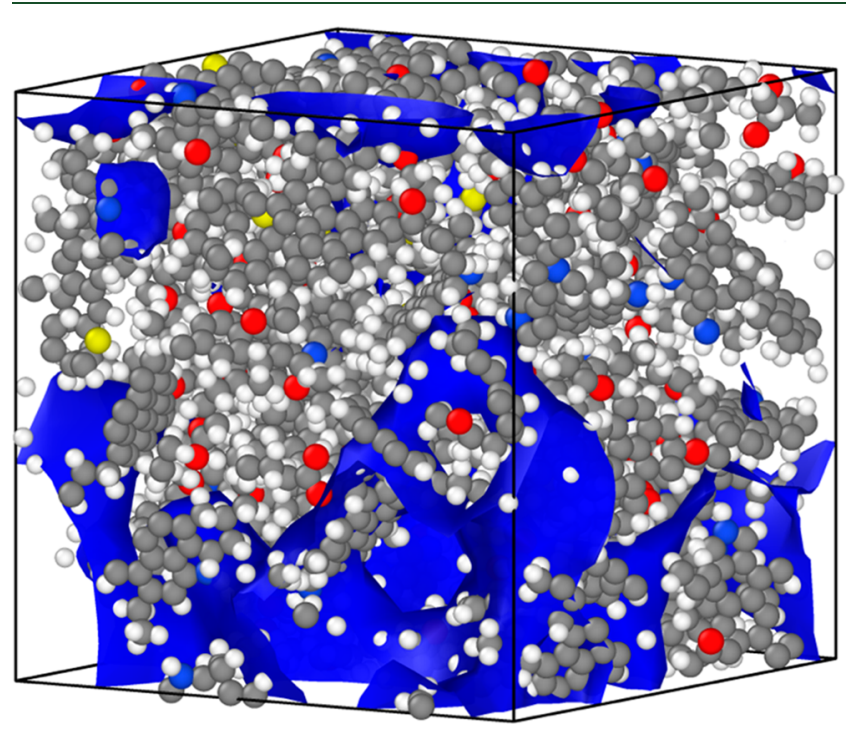

Figure 2. Configuration of the type II kerogen matrix. Atom representation: gray for carbon atoms, white for hydrogen atoms, red for oxygen atoms, blue for nitrogen atoms, and yellow for sulfur atoms. Pore surfaces are colored in blue.

kerogen matrix is highly heterogeneous and sufficient to represent complex realistic kerogen. The kerogen matrix under a wide range of moisture contents from 0.5 to $6.0 \mathrm{wt} \%$ as well as the kerogen matrix filled with saline water were also created to study the effects of the moisture content and salinity on the methane adsorption. A higher $\mathrm{NaCl}$ salinity $(2.5-6 \mathrm{~mol} / \mathrm{L})$ than typical subsurface water was contained in our systems to reduce statistical bias and obtain reliable simulation results. During the simulations of methane adsorption, the kerogen matrix was held rigid but the water molecules and $\mathrm{Na}^{+}$and $\mathrm{Cl}^{-}$ions were allowed to move.

2.2.2. Other Molecules. The methane molecule was modeled using transferable potentials for phase equilibria (TraPPE) force field parameters ${ }^{40}$ with the united-atom representation with the effect of hydrogens included in the central carbon atom. For water molecules, the simple-point charge extended model $(\mathrm{SPC} / \mathrm{E})^{41}$ was chosen, in which the bond length of the $\mathrm{O}-\mathrm{H}$ bond is $1 \AA$ and the degree of the $\mathrm{H}-\mathrm{O}-\mathrm{H}$ angle is $109.47^{\circ}$. In the simulations, the SHAKE algorithm was adopted to fix the bond and angle. The CLAYFF force field ${ }^{42}$ was applied to describe the properties of $\mathrm{NaCl}$. Besides, to calculate the void volume of the kerogen matrix, helium was used as a probe molecule. A single-site model ${ }^{43}$ was employed to describe the helium molecules. The force field parameters of $\mathrm{CH}_{4}, \mathrm{H}_{2} \mathrm{O}, \mathrm{He}$, and $\mathrm{NaCl}$ are summarized in Table S1 of the Supporting Information. LorentzBertherlot mixing rules ${ }^{44}$ were employed to calculate interactions between unlike atoms. The density of bulk methane, water, and helium as a function of the temperature and pressure were also calculated to validate the force field as well as the accuracy of the GCMC calculation. As presented in Figure 3, the results match fairly

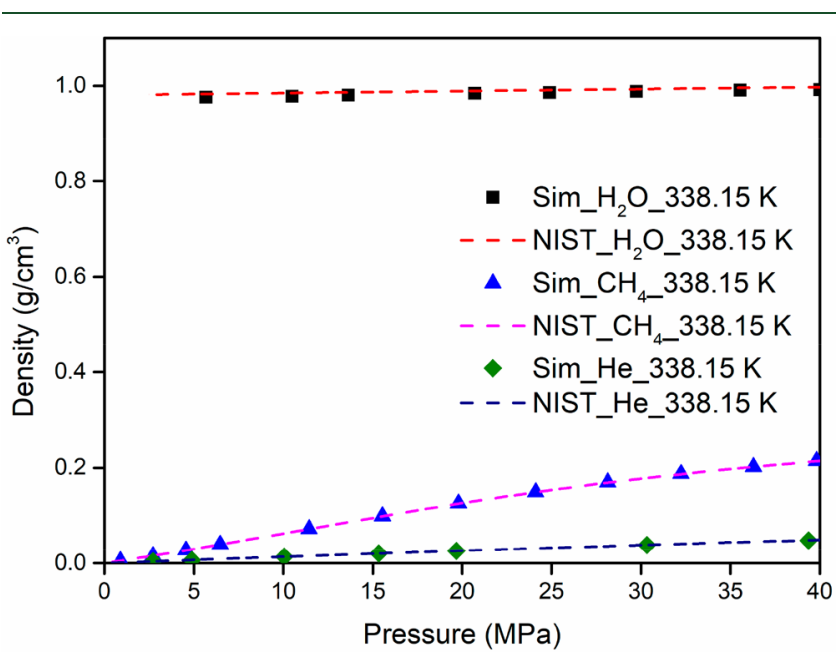

Figure 3. Validation for the pressure-density relationship for the TraPPE methane model, ${ }^{40}$ SPC/E $\mathrm{H}_{2} \mathrm{O}$ model, ${ }^{46}$ and helium model. $^{47}$

well with the National Institute of Standards and Technology (NIST) database. ${ }^{45}$ Further verification using the radial distribution function (RDF) is shown in Figure S1 of the Supporting Information.

2.3. Simulation Details. In this part, methodologies of the MD simulation to produce molecular structures and the GCMC simulation to investigate the methane adsorption properties are illustrated in detail. All simulations were performed using the largescale atomic/molecular massively parallel simulator (LAMMPS) package. $^{48}$

In the MD simulations, a time step of $1 \mathrm{fs}$ was chosen in both NVT and NPT ensembles. The temperature and pressure were regulated using a Nosé-Hoover thermostat ${ }^{49}$ and Nosé-Hoover barostat, ${ }^{50}$ respectively, both with a damping constant of $100 \mathrm{fs}$. The velocity Verlet integrator was adopted to update velocities and positions of atoms through solving Newton's equation of motion. Periodic boundary conditions were employed in all three directions. Lennard-Jones interactions were calculated with a cutoff distance of $12 \AA$, and analytical tail corrections were applied. ${ }^{51}$ A particleparticle and particle-mesh (PPPM) solver with a precision of $1 \times$ $10^{-4}$ was adopted for the calculation of long-range electrostatic interactions.

For the GCMC simulations, the position of the kerogen matrix was fixed, while methane molecules were translated and inserted/deleted with a probability of $0.5,0.25$, and 0.25 , respectively. In each GCMC cycle, 1000 GCMC exchanges (insertions and deletions were attempted with equal probability) and 1000 GCMC moves (only translations were attempted as a result of the united atom model for methane) were achieved.

An estimate of the effective pore volume of the kerogen matrix was given using helium adsorption. ${ }^{52}$ Helium is assumed to be a nonadsorbing gas because the adsorption of helium in microporous media could be negligible at temperatures close to room temperature. ${ }^{53}$ The pore volume was determined on the basis of the number of helium molecules filled in the kerogen pores

$$
V_{\mathrm{p}}=\frac{\left\langle N_{\mathrm{He}}\right\rangle}{\rho_{\mathrm{He}, \text { bulk }}}
$$

where $\left\langle N_{\mathrm{He}}\right\rangle$ is the ensemble-averaged number of helium molecules filled in kerogen nanopores and $\rho_{\mathrm{He}, \text { bulk }}$ is the number density of bulk helium at given temperatures and pressures. In this work, tests to calculate the pore volume were performed up to a pressure of $30 \mathrm{MPa}$ 
to check its constancy with pressure. The effective pore volume of the kerogen matrix is $8.18 \pm 0.02 \mathrm{~nm}^{3}$ based on the average over several pressures. Additional details of the adsorption of helium and the calculation of pore volume were given in Figures S2 and S3 of the Supporting Information.

\section{RESULTS AND DISCUSSION}

In section 3.1, physical properties of the kerogen structure constructed by MD simulations are validated and presented. Methane adsorption isotherms in dry kerogens under a large range of pressures and four temperatures are analyzed in section 3.2. The methane adsorption properties and microscopic distribution of water molecules in moisture-equilibrated kerogens are discussed in section 3.3. Finally, section 3.4 focuses on the effects of salinity on the methane adsorption capacity.

3.1. Kerogen Model Validation. To evaluate the reasonability of our kerogen model, further comparisons are made from physical density to methane adsorption isotherms between simulated results of our kerogen model and experimental data. The density of the kerogen matrix is 1.22 $\mathrm{g} / \mathrm{cm}^{3}$, which is within the range of the experimental value of mature shales $\left(1.18-1.35 \mathrm{~g} / \mathrm{cm}^{3}\right) .^{54}$ Besides, methane adsorption isotherms are calculated and compared to published experimental data. ${ }^{14,55}$ In experiments, the adsorption properties obtained by the conventional sorption measurement are evaluated by excess adsorption capacities. To make comparisons to experimental results, we convert the total adsorption capacities obtained in GCMC simulations to excess adsorption capacity through subtracting the amount of free gas in the effective pore volume $V_{\mathrm{p}}$ from $n_{\text {tot }}{ }^{52}$

$$
n_{\text {exc }}=n_{\text {tot }}-\rho_{\text {bulk }} V_{\mathrm{p}}
$$

where $n_{\text {exc }}$ denotes the excess adsorption capacity, $n_{\text {tot }}$ refers to the total adsorption capacity, $\rho_{\text {bulk }}$ is the bulk density of adsorbate, and $V_{\mathrm{p}}$ is from helium adsorption, as described in section 2.3. Comparisons of excess adsorption isotherms at 338 $\mathrm{K}$ between our simulation results and experimental data ${ }^{14,55}$ are plotted in Figure 4. The experimental data for methane adsorption are based on kerogen samples from Posidonia shales, ${ }^{56}$ Woodford shale, ${ }^{12}$ Sichuan Basin, ${ }^{57}$ and shale samples from Geverik shale, ${ }^{55}$ Barnett shale, and Carboniferous shale. ${ }^{14}$ As shown in Figure 4, similar trends for excess adsorption isotherms can be observed from the simulated and

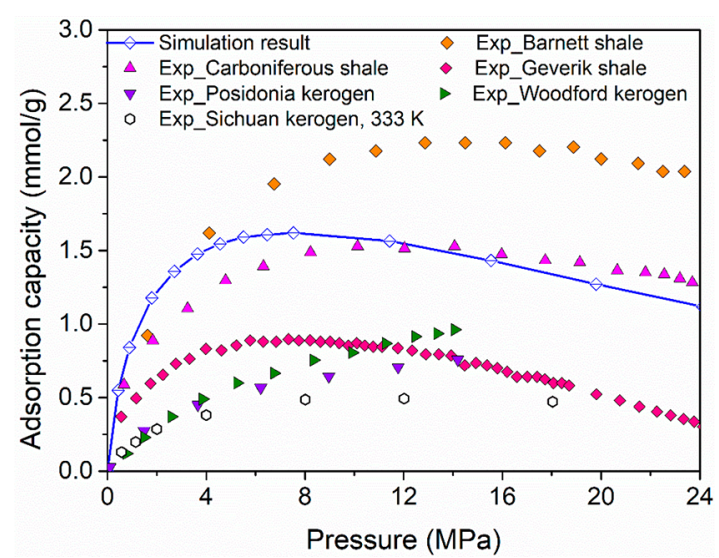

Figure 4. Comparison of methane excess adsorption isotherms at 338 $\mathrm{K}$ between results of simulations and experiments. experimental results, in which the excess adsorption capacity rises at the beginning and reaches a peak at about $5 \mathrm{MPa}$. Afterward, it drops with increasing pressure. In the experimental data of Posidonia and Woodford kerogens, the pressure range is not large enough for the isotherms to reach the excess maximum; therefore, the decrease in excess adsorption isotherms cannot be observed. The difference in adsorption values may be attributed to the diversity in thermal maturity, porosity, and shale composition because the presence of inorganic materials in shale samples, such as clays, silica, and carbonates, could decrease the adsorption amount of methane in experiments. Above all, the kerogen model is proven to have the ability to represent realistic kerogen and can be used to investigate methane adsorption behaviors.

3.2. Methane Adsorption on Dry Kerogen. 3.2.1. Total Adsorption. Figure 5 displays the total adsorption isotherms of

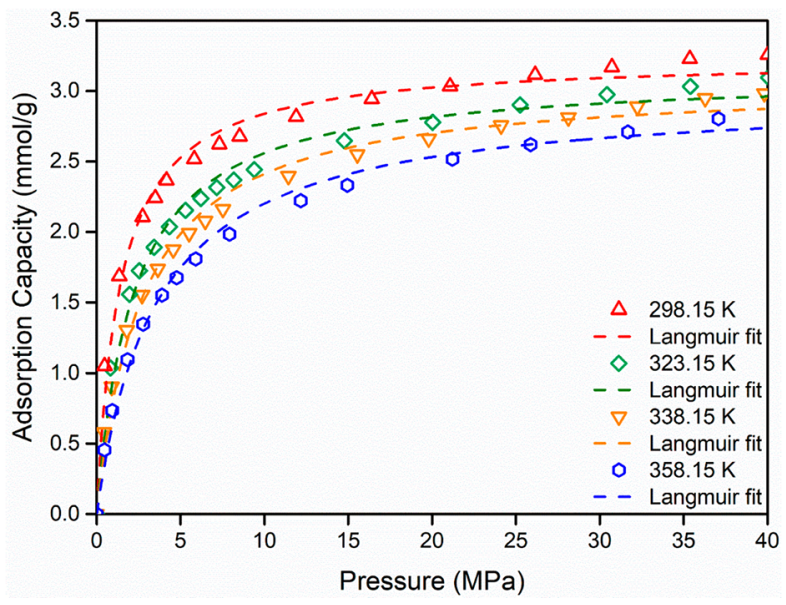

Figure 5. $\mathrm{CH}_{4}$ adsorption isotherms at four different temperatures. Points are results of simulation, and lines are results of Langmuir fitting.

methane in the dry kerogen matrix at different temperatures ranging from 298.15 to $358.15 \mathrm{~K}$ under pressures up to 40 $\mathrm{MPa}$. The total adsorption capacity refers to the total amount of gas confined in the pore structure, including both adsorbed and bulk gas phases, per gram of adsorbent. As shown in Figure 5, the total adsorption isotherms of methane are observed to fit the shape of the Langmuir isotherm. ${ }^{58}$ Therefore, we parametrize the total adsorption data of methane using the Langmuir model, ${ }^{59}$ which is commonly used and widely accepted in the petroleum industry ${ }^{60}$

$$
n(T)=n_{\mathrm{L}} \frac{p}{p+p_{\mathrm{L}}(T)}
$$

where $n(T)$ denotes the adsorption capacity at temperature $T$ and pressure $p, p_{\mathrm{L}}(T)$ is the Langmuir pressure, corresponding to the pressure at which half of the sorption sites are occupied, and $n_{\mathrm{L}}$ denotes the maximum Langmuir capacity. The adsorption quantity is normalized by the mass of the adsorbent. Table 1 summarizes the results of the Langmuir equation fitting using the least squares method. The Langmuir adsorption model is observed to have good performance in predicting methane adsorption isotherms. The total adsorption capacity increases as the pressure increases and tends to reach equilibrium under a relatively high pressure. The total adsorption capacity decreases with the increase of the 
Table 1. Langmuir Fitting Results of Methane Adsorption in Dry Kerogens

\begin{tabular}{lllll}
\multicolumn{1}{c}{$T(\mathrm{~K})$} & 298.15 & 323.15 & 338.15 & 358.15 \\
$P_{\mathrm{L}}(\mathrm{MPa})$ & 1.40 & 2.21 & 2.72 & 3.53 \\
$n_{\mathrm{L}}(\mathrm{mmol} / \mathrm{g})$ & 3.24 & 3.13 & 3.07 & 2.98 \\
$R^{2}$ & 0.987 & 0.988 & 0.991 & 0.992
\end{tabular}

temperature as a result of the exothermic nature of the adsorption process. At higher temperatures, the methane molecules also have higher energy to escape from the adsorption layer.

3.2.2. Excess Adsorption. Figure 6 presents the $\mathrm{CH}_{4}$ excess adsorption capacities calculated using eq 2 . From the excess

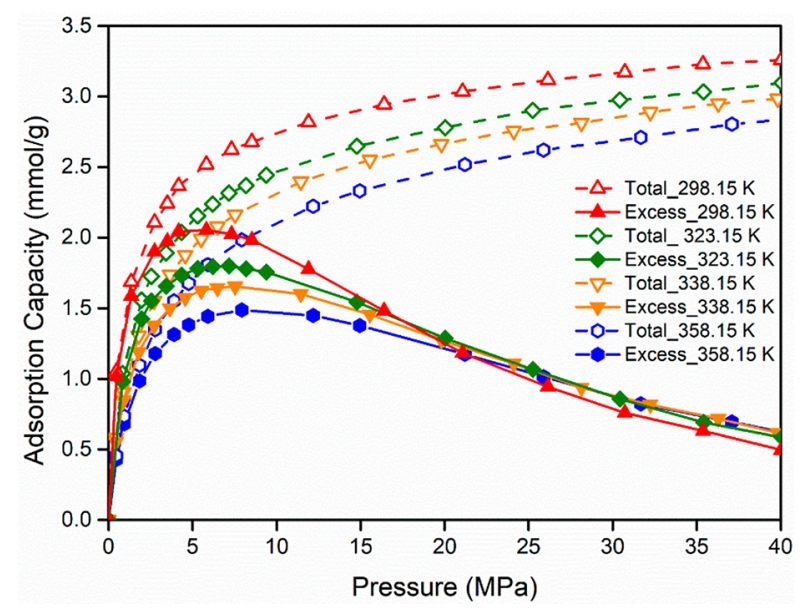

Figure 6. $\mathrm{CH}_{4}$ adsorption isotherms in dry kerogen at four temperatures.

adsorption isotherms, the excess adsorption isotherms at different temperatures follow the same trend as the excess adsorption amount increases with the rising pressure and there appears a maximum in the excess adsorption isotherm at around $5 \mathrm{MPa}$, and after that, the excess adsorption amount decreases because the bulk density rises faster than the adsorbed density. Besides, an increase in the temperature results in the change in the shape of adsorption isotherms. The maximum in excess adsorption is higher at low temperatures compared to that at high temperatures and shifts to a higher pressure with the increasing temperature. This is in accordance with recent studies on kerogen in both experiments ${ }^{12}$ and simulations. ${ }^{25}$ In this work, we extend the pressure range to 40 $\mathrm{MPa}$, and it is found that, as the pressure increases further, the excess adsorption capacity becomes larger at the higher temperature and the lowest value is observed at the lowest temperature, which is $298.15 \mathrm{~K}$ in the current study. This is because the methane bulk density at $298.15 \mathrm{~K}$ rises relatively faster with increasing pressure.

3.2.3. Thermodynamic Properties. The isosteric heat of adsorption $q$ and the standard entropy of adsorption $\Delta s^{0}$ are two critical thermodynamic parameters for characterization and optimization of an adsorption process. The two thermodynamic parameters can be derived from eq 4 using the adsorption isotherms at different temperatures ${ }^{12,61}$

$$
\frac{1}{p_{\mathrm{L}}}=\exp \left(\frac{q}{R T}+\frac{\Delta s^{0}}{R}\right)
$$

where $q$ denotes the isosteric heat of adsorption, $\Delta s^{0}$ denotes the standard entropy of adsorption, $p_{\mathrm{L}}$ denotes the Langmuir pressure, and $R$ is the gas constant. On the basis of the isotherms, a linear correlation can be clearly seen in Figure 7

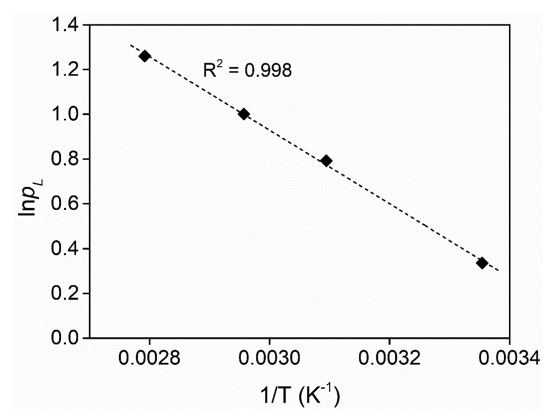

Figure 7. Plot of $\ln p_{\mathrm{L}}$ against $1 / T$ for methane adsorption in dry kerogen.

between the natural logarithm of the Langmuir pressure $p_{\mathrm{L}}$ and the reciprocal of the temperature $(1 / T)$, and the corresponding correlation coefficient is $R^{2}=0.998$. Then, the isosteric heat of adsorption and standard entropy are determined by the slope and intercept, respectively. The isosteric heat of adsorption and the standard entropy of adsorption are calculated to be $13.7 \mathrm{~kJ} \mathrm{~mol}^{-1}$ and $-48.7 \mathrm{~kJ} \mathrm{~mol}^{-1} \mathrm{~K}^{-1}$, respectively. The value of isosteric heat of adsorption is within the range of the previously reported experimental quantities for kerogen $\left(10.3-21.9 \mathrm{~kJ} \mathrm{~mol}^{-1}\right) .{ }^{12,56}$ Besides, the simulated standard entropy of adsorption also shows good consistency with the values published by Zou et al. ${ }^{62}$ from -42 to $74.7 \mathrm{~kJ}$ $\mathrm{mol}^{-1} \mathrm{~K}^{-1}$

3.3. Effects of Moisture on Methane Adsorption. Adsorption of methane in kerogens of different moisture contents in the range of $0-6$ wt $\%$ at $338.15 \mathrm{~K}$ and up to 40 $\mathrm{MPa}$ is studied by GCMC simulations, and the isotherms of total adsorption are presented in Figure 8. It is obvious that the

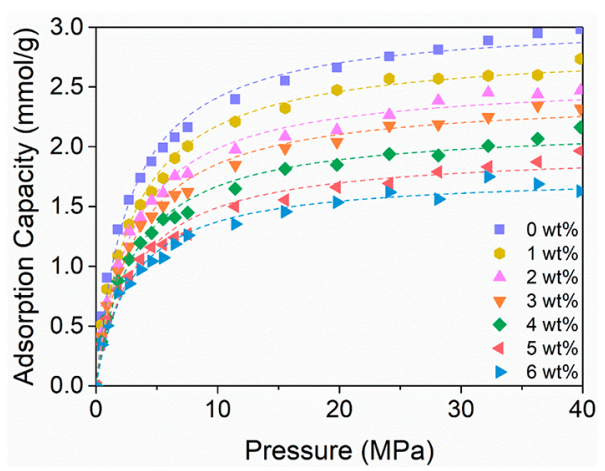

Figure 8. $\mathrm{CH}_{4}$ adsorption isotherms under different moisture contents at $338.15 \mathrm{~K}$. Points are results of simulation, and lines are results of Langmuir fitting.

higher moisture content corresponds to the decreased adsorption capacity of methane, which is consistent with the results reported in previous studies. ${ }^{13,25,28}$ The Langmuir adsorption model (eq 3) provides a very good representation of the total adsorption isotherm. The fitting Langmuir parameters are listed in Table 2. The maximum Langmuir capacity ranges from 1.76 to $3.07 \mathrm{mmol} / \mathrm{g}$, and a $42.5 \%$ reduction is found in the maximum adsorption capacity of 
Table 2. Langmuir Constants of Methane Adsorption on Moisture-Equilibrated Kerogens at 338.15 K

\begin{tabular}{lccc} 
moisture content $(\mathrm{wt} \%)$ & $n_{\mathrm{L}}(\mathrm{mmol} / \mathrm{g})$ & $P_{\mathrm{L}}(\mathrm{MPa})$ & $R^{2}$ \\
0 & 3.07 & 2.72 & 0.991 \\
0.5 & 2.99 & 2.79 & 0.992 \\
1 & 2.83 & 3.03 & 0.992 \\
1.5 & 2.76 & 2.83 & 0.991 \\
2 & 2.57 & 2.94 & 0.991 \\
2.5 & 2.54 & 3.00 & 0.990 \\
3 & 2.43 & 3.07 & 0.991 \\
3.5 & 2.31 & 2.92 & 0.990 \\
4 & 2.18 & 3.05 & 0.990 \\
5 & 1.97 & 3.20 & 0.981 \\
6 & 1.76 & 2.85 & 0.984 \\
\hline
\end{tabular}

methane after moisture equilibration of $6.0 \mathrm{wt} \%$. The excess adsorption isotherms of different moisture contents are plotted in Figure S4 of the Supporting Information. Like in the dry conditions, the excess adsorption capacities pass through a maximum and then decrease as the pressure further increases. The methane excess adsorption decreases with increasing moisture contents. When the moisture content is over $3 \mathrm{wt} \%$, the excess adsorption isotherms become negative under high pressures. This is because the adsorbed density of methane in moist kerogen of high moisture content is less than the methane bulk density. To further quantify the effects of moisture contents on methane adsorption, the maximum Langmuir capacity of different moisture contents and reduction of the adsorption capacity compared to dry kerogen in the function of moisture contents are depicted in Figure 9.

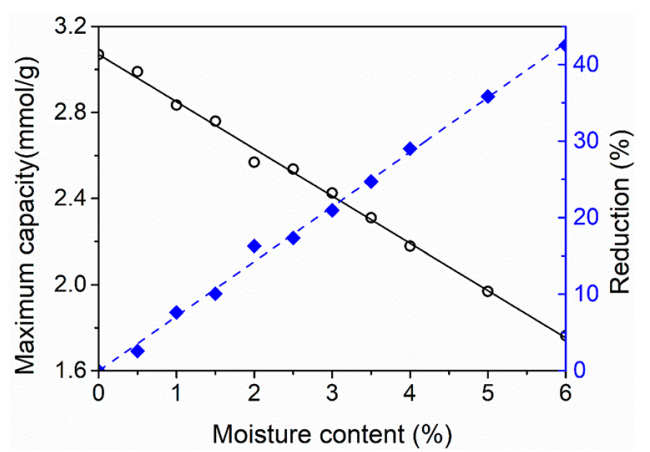

Figure 9. Langmuir maximum adsorption capacity of different moisture contents (black) and reduction in adsorption capacity as a function of moisture contents (blue) at $338.15 \mathrm{~K}$.

The methane maximum Langmuir capacity decreases linearly with increasing moisture contents, with a correlation coefficient of $R^{2}>0.996$. The reduction in adsorption capacity for moisture-equilibrated kerogens also increases as the moisture content increases, which results from the adsorption of water in the kerogen nanopores. To verify this argument, density distribution of water molecules in moisture-equilibrated kerogen at $3 \mathrm{wt} \%$ moisture content and the decrease in methane density distribution compared to dry kerogen are illustrated in Figure 10, where distances are measured along the $X$ direction and the position $X=0$ corresponds to the center of the kerogen matrix. The temperature and pressure are $338.15 \mathrm{~K}$ and $40 \mathrm{MPa}$, respectively. A significant overlap can be observed between the distribution of water molecules and distribution of the decreased density of methane adsorbed in

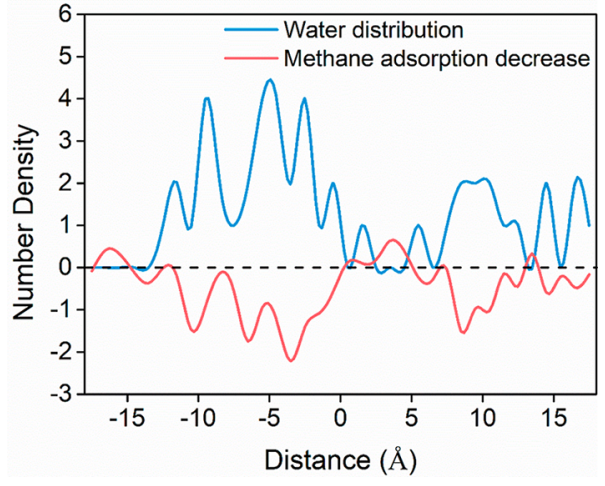

Figure 10. Density distribution of water molecules in 3 wt \% moisture-equilibrated kerogen (blue) and decrease in methane adsorption density distribution (red) at $338.15 \mathrm{~K}$, with $p=40 \mathrm{MPa}$.

the kerogen matrix, which demonstrates that the water molecules occupy the adsorption sites in the kerogen matrix and block the access of methane to the nanopores, which results in the decrease in the methane adsorption capacity in kerogens. In some regions, a very small increase in the methane adsorption density can be observed in the moistureequilibrated conditions, but the corresponding water density is close to zero. The difference in methane number density can be attributed to the fluctuation of methane molecules from 0 to 1 during simulations.

3.4. Effects of Salinity on Methane Adsorption. As mentioned in the Introduction, previous studies ${ }^{29-32}$ suggest that the composition of underground water contains not only water but also a certain amount of salts. In this section, we quantitatively analyze the effects of salinity on methane adsorption in kerogens, in which the $\mathrm{NaCl}$ aqueous solution is chosen for its abundance in underground water. Total adsorption isotherms of methane in moisture-equilibrated kerogens of several salinities up to $6 \mathrm{~mol} / \mathrm{L}$ are plotted in Figure 11, where the moisture content in kerogen is $3 \mathrm{wt} \%$.

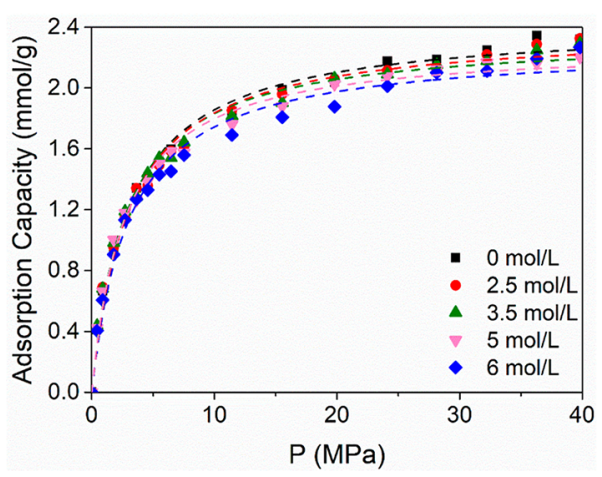

Figure 11. $\mathrm{CH}_{4}$ adsorption isotherms of different salinities with the moisture content of 3 wt $\%$ at $338.15 \mathrm{~K}$. Points are results of simulation, and lines are results of Langmuir fitting.

The adsorption isotherms are fitted using the least squares method based on the Langmuir equation. As shown in Figure 11 , in comparison to the total adsorption capacity in moist kerogen filled with pure water, namely, $0 \mathrm{~mol} / \mathrm{L}$, the $\mathrm{CH}_{4}$ adsorption capacity is further reduced with the presence of salinity. The relationship between the maximum $\mathrm{CH}_{4}$ Langmuir adsorption capacity and salinity is presented in Figure 12. With increasing salinity, the maximum $\mathrm{CH}_{4}$ 


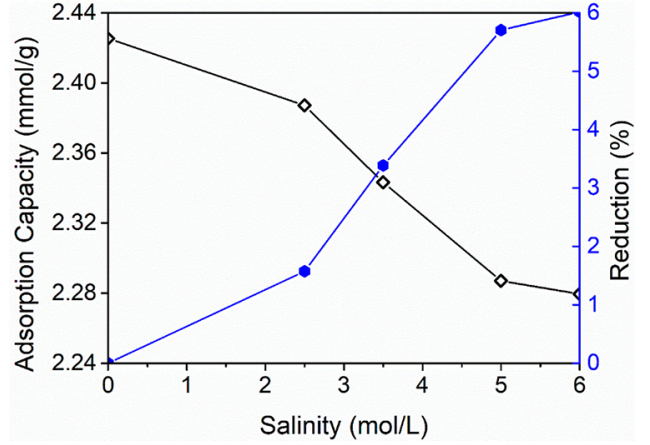

Figure 12. Langmuir maximum adsorption capacity of different salinities with the moisture content of $3 \mathrm{wt} \%$ (black) and reduction in adsorption capacity as a function of salinities (blue). The temperature is $338.15 \mathrm{~K}$.

Langmuir adsorption capacity declines slowly at first and then the decrease rate increases rapidly and finally comes to a relatively stable stage. The corresponding adsorption capacity reduction curve is also shown in Figure 12. The adsorption capacities reduce about 1.6, 3.4, 5.7, and $6.0 \%$ under the salinities of $2.5,3.5,5$, and $6 \mathrm{~mol} / \mathrm{L}$, respectively. This indicates that a higher salinity results in a larger decline in the adsorption capacity. This can be explained by the decreasing solubility of methane in saline water. Previous literature had reported that methane has a very low solubility in water and the addition of $\mathrm{NaCl}$ to water further decreases the $\mathrm{CH}_{4}$ solubility. ${ }^{63-65}$ As a result, careful consideration should be taken to the effects of salinity as well as the moisture contents in kerogens to guarantee the accuracy when evaluating the shale gas in place.

To better understand the effects of moisture and salinity, the adsorption of methane in kerogens by varying moisture contents at the same salinity is also investigated. The adsorption isotherms of 3 and 6 wt \% with and without salinity are chosen as a typical case and presented in Figure 13.

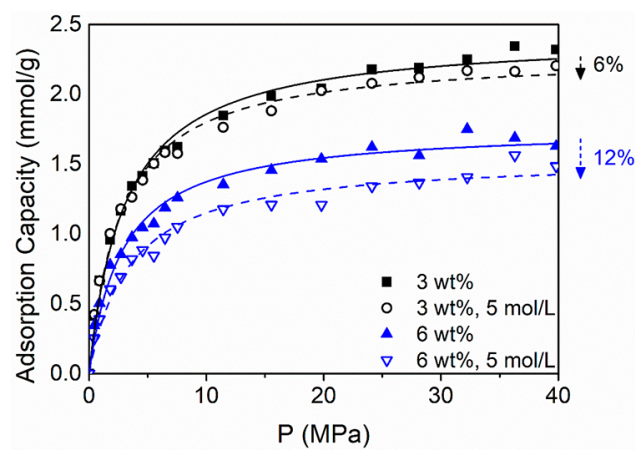

Figure 13. $\mathrm{CH}_{4}$ adsorption isotherms of different moisture contents and salinities at $338.15 \mathrm{~K}$. Points are results of simulation, and lines are results of Langmuir fitting. The reduction in adsorption capacity from the pure water- to the saline water-equilibrated kerogens is shown, too.

The Langmuir equation is used to parametrize the methane adsorption isotherms. Results of other moisture contents can be found in Figure S7 of the Supporting Information. Reductions of 6 and $12 \%$ are measured for moisture contents of 3 and $6 \mathrm{wt} \%$, respectively. Summarization of the maximum $\mathrm{CH}_{4}$ adsorption capacities of different moisture contents at a salinity of $5 \mathrm{~mol} / \mathrm{L}$ and full comparison to that of zero salinity are shown in Figure 14. Under the salinity of $5 \mathrm{~mol} / \mathrm{L}$, the total adsorption capacities of $\mathrm{CH}_{4}$ are 2.29, 1.98, 1.78, and 1.55

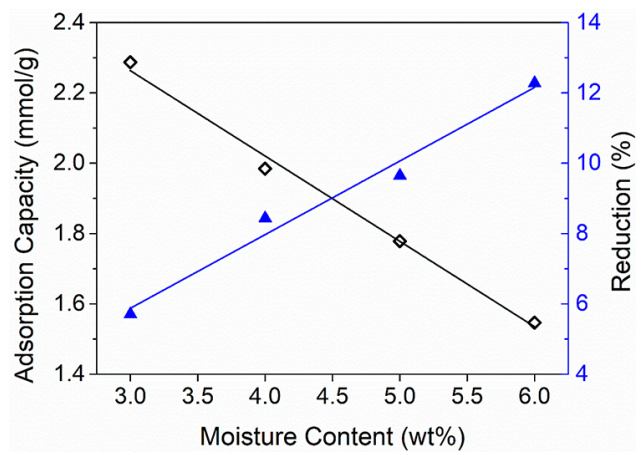

Figure 14. Langmuir maximum adsorption capacity of different moisture contents with the salinity of $5 \mathrm{~mol} / \mathrm{L}$ (black) and reduction in adsorption capacity as a function of moisture contents (blue). The temperature is $338.15 \mathrm{~K}$.

$\mathrm{mmol} / \mathrm{g}$ in 3.0, 4.0, 5.0, and $6.0 \mathrm{wt} \%$ moisture-equilibrated kerogens, respectively. With the same salinity, the reduction in adsorption capacity increases as the moisture content increases. An approximately linear trend can be observed $\left(R^{2}\right.$ $>0.97)$. The reduction caused by different moisture contents is much larger than that of the different salinities. It can be concluded that the moisture content has a larger influence on methane adsorption capacity in kerogens compared to salinity.

\section{CONCLUSION}

In the present work, realistic kerogen matrixes at various moisture contents $(0-6.0 \mathrm{wt} \%)$ and different salinities (0-6 $\mathrm{M} \mathrm{NaCl}$ ) are generated using a combination of $\mathrm{MD}$ and GCMC simulations. We investigate the adsorption properties of methane in both dry and moisture-equilibrated kerogens. Effects of moisture and salinity on methane adsorption are discussed in detail. Simulations are carried out under a larger range of pressures (up to $40 \mathrm{MPa}$ ) than attempted in previous studies. ${ }^{25-28}$ Both pressures and temperatures are set to realize typical reservoir conditions. The main conclusions drawn from our study are as follows: (1) The adsorption of methane in dry kerogens indicates that, under relatively low pressures, the $\mathrm{CH}_{4}$ excess adsorption capacity decreases with the increase of the temperature as reported in previous studies. ${ }^{25,26}$ When the pressure rises above $25 \mathrm{MPa}$, the excess adsorption capacity of methane is observed to be larger at the higher temperature, which can be explained by the competition between the methane bulk density and adsorbed density. Under relatively high pressures, the bulk density of methane at lower temperatures rises relatively faster than the adsorbed density with increasing pressure. (2) Adsorption of methane in kerogen matrixes is greatly reduced by the presence of water. A reduction of $42.5 \%$ is observed in $\mathrm{CH}_{4}$ maximum adsorption capacity of kerogen matrixes at $6.0 \mathrm{wt} \%$ moisture content. Besides, results suggest a linear relationship between the reduction in the methane adsorption capacity and the moisture content. The areas of water molecules are observed to coincide with the areas of decrease in methane adsorption, which demonstrates that water molecules occupy the adsorption sites in the kerogen matrix and lead to the decline in $\mathrm{CH}_{4}$ adsorption capacity in kerogens. (3) Effects of salinity are also investigated. The $\mathrm{NaCl}$ aqueous solution is chosen to 
represent the subsurface water. Our results show that the presence of $\mathrm{Na}^{+}$and $\mathrm{Cl}^{-}$further decrease the methane adsorption capacity, which is attributed to the reduced solubility of methane in water. The higher salinity in the kerogen matrix leads to a larger reduction in $\mathrm{CH}_{4}$ adsorption capacity. Effects of salinity cannot be ignored when assessing shale gas potential of reservoirs, although it seems to have a less significant effect on methane adsorption compared to that of the moisture content in the kerogen matrix.

\section{ASSOCIATED CONTENT}

\section{S Supporting Information}

The Supporting Information is available free of charge on the ACS Publications website at DOI: 10.1021/acs.energyfuels.9b00392.

RDF verification of $\mathrm{CH}_{4}$ and $\mathrm{H}_{2} \mathrm{O}$, additional details of effective pore volume calculation, $\mathrm{CH}_{4}$ excess adsorption isotherms under different moisture contents and salinities, additional $\mathrm{CH}_{4}$ total adsorption isotherms of different moisture contents and salinities, thermodynamic properties in the moist and saline conditions, and force-field parameters and adsorption data (PDF)

\section{AUTHOR INFORMATION}

\section{Corresponding Author}

*E-mail: k.luo@ucl.ac.uk.

\section{ORCID}

Kai H. Luo: 0000-0003-4023-7259

\section{Notes}

The authors declare no competing financial interest.

\section{ACKNOWLEDGMENTS}

Support from the Ministry of Science and Technology (MOST) National Key Research and Development Program (Project No. 2016YFB0600805) and the Center for Combustion Energy at Tsinghua University is gratefully acknowledged. The simulations were partly performed on the High-Performance Parallel Computer supported by the Tsinghua High-Performance Computing (HPC) Platform. Additional support from the U.K. Engineering and Physical Sciences Research Council under the Project U.K. Consortium on Mesoscale Engineering Sciences (UKCOMES, Grant No. $\mathrm{EP} / \mathrm{R} 029598 / 1)$ is gratefully acknowledged.

\section{REFERENCES}

(1) Vidic, R. D.; Brantley, S. L.; Vandenbossche, J. M.; Yoxtheimer, D.; Abad, J. D. Impact of Shale Gas Development on Regional Water Quality. Science (Washington, DC, U. S.) 2013, 340 (6134), 1235009.

(2) Melikoglu, M. Shale Gas: Analysis of Its Role in the Global Energy Market. Renewable Sustainable Energy Rev. 2014, 37, 460-468.

(3) U.S. Energy Information Administration (EIA). Natural Gas Gross Withdrawals and Production; EIA: Washington, D.C., 2019; https://www.eia.gov/dnav/ng/ng_prod_sum_a_EPG0_FGW_ mmcf a.htm.

(4) Ross, D. J. K.; Bustin, R. M. The Importance of Shale Composition and Pore Structure upon Gas Storage Potential of Shale Gas Reservoirs. Mar. Pet. Geol. 2009, 26 (6), 916-927.

(5) Vandenbroucke, M.; Largeau, C. Kerogen Origin, Evolution and Structure. Org. Geochem. 2007, 38 (5), 719-833.

(6) Ortiz Cancino, O. P.; Peredo Mancilla, D.; Pozo, M.; Pérez, E.; Bessieres, D. Effect of Organic Matter and Thermal Maturity on Methane Adsorption Capacity on Shales from the Middle Magdalena Valley Basin in Colombia. Energy Fuels 2017, 31 (11), 11698-11709.
(7) Curtis, J. B. Fractured Shale-Gas Systems. AAPG Bull. 2002, 86 (11), 1921-1938.

(8) Odusina, E. O.; Sondergeld, C. H.; Rai, C. S. NMR Study of Shale Wettability. Proceedings of the Canadian Unconventional Resources Conference; Calgary, Alberta, Canada, Nov 15-17, 2011; DOI: $10.2118 / 147371-M S$.

(9) Parfenova, T. M.; Kontorovich, A. E.; Borisova, L. S.; Melenevskii, V. N. Kerogen from the Cambrian Deposits of the Kuonamka Formation (Northeastern Siberian Platform). Russ. Geol. Geophys. 2010, 51 (3), 277-285.

(10) Chalmers, G. R.; Bustin, M. R. The Effects and Distribution of Moisture in Gas Shale Reservoirs Systems. Proceedings of the AAPG Annual Convention and Exhibition; New Orleans, LA, April 11-14, 2010.

(11) Ruppert, L. F.; Sakurovs, R.; Blach, T. P.; He, L.; Melnichenko, Y. B.; Mildner, D. F. R.; Alcantar-Lopez, L. A USANS/SANS Study of the Accessibility of Pores in the Barnett Shale to Methane and Water. Energy Fuels 2013, 27 (2), 772-779.

(12) Zhang, T.; Ellis, G. S.; Ruppel, S. C.; Milliken, K.; Yang, R. Effect of Organic-Matter Type and Thermal Maturity on Methane Adsorption in Shale-Gas Systems. Org. Geochem. 2012, 47, 120-131.

(13) Li, X.; Krooss, B. M. Influence of Grain Size and Moisture Content on the High-Pressure Methane Sorption Capacity of Kimmeridge Clay. Energy Fuels 2017, 31 (11), 11548-11557.

(14) Gasparik, M.; Bertier, P.; Gensterblum, Y.; Ghanizadeh, A.; Krooss, B. M.; Littke, R. Geological Controls on the Methane Storage Capacity in Organic-Rich Shales. Int. J. Coal Geol. 2014, 123, 34-51.

(15) Tan, J.; Horsfield, B.; Fink, R.; Krooss, B.; Schulz, H. M.; Rybacki, E.; Zhang, J.; Boreham, C. J.; Van Graas, G.; Tocher, B. A. Shale Gas Potential of the Major Marine Shale Formations in the Upper Yangtze Platform, South China, Part III: Mineralogical, Lithofacial, Petrophysical, and Rock Mechanical Properties. Energy Fuels 2014, 28 (4), 2322-2342.

(16) Wu, H.; Chen, J.; Liu, H. Molecular Dynamics Simulations about Adsorption and Displacement of Methane in Carbon Nanochannels. J. Phys. Chem. C 2015, 119 (24), 13652-13657.

(17) Lin, K.; Yuan, Q.; Zhao, Y.-P. Using Graphene to Simplify the Adsorption of Methane on Shale in MD Simulations. Comput. Mater. Sci. 2017, 133, 99-107.

(18) Hu, Y.; Devegowda, D.; Sigal, R. A Microscopic Characterization of Wettability in Shale Kerogen with Varying Maturity Levels. J. Nat. Gas Sci. Eng. 2016, 33, 1078-1086.

(19) Hu, Y.; Devegowda, D.; Striolo, A.; Phan, A.; Ho, T. A.; Civan, F.; Sigal, R. The Dynamics of Hydraulic Fracture Water Confined in Nano-Pores in Shale Reservoirs. J. Unconv. Oil Gas Resour. 2015, 9, $31-39$.

(20) Hu, Y.; Devegowda, D.; Striolo, A.; Phan, A.; Ho, T. A.; Civan, F.; Sigal, R. F. Microscopic Dynamics of Water and Hydrocarbon in Shale-Kerogen Pores of Potentially Mixed Wettability. SPE J. 2014, 20 (01), 112-124.

(21) Liu, Y.; Wilcox, J. $\mathrm{CO}_{2}$ Adsorption on Carbon Models of Organic Constituents of Gas Shale and Coal. Environ. Sci. Technol. 2011, 45 (2), 809-814.

(22) Liu, Y.; Wilcox, J. Molecular Simulation Studies of CO Adsorption by Carbon Model Compounds for Carbon Capture and Sequestration Applications. Environ. Sci. Technol. 2013, 47 (1), 95101.

(23) Zhang, H.; Cao, D. Molecular Simulation of Displacement of Shale Gas by Carbon Dioxide at Different Geological Depths. Chem. Eng. Sci. 2016, 156, 121-127.

(24) Severson, B. L.; Snurr, R. Q. Monte Carlo Simulation of $n$ -Alkane Adsorption Isotherms in Carbon Slit Pores. J. Chem. Phys. 2007, 126 (13), 134708.

(25) Zhao, T.; Li, X.; Zhao, H.; Li, M. Molecular Simulation of Adsorption and Thermodynamic Properties on Type II Kerogen: Influence of Maturity and Moisture Content. Fuel 2017, 190, 198207. 
(26) Zhao, T.; Li, X.; Ning, Z.; Zhao, H.; Li, M. Molecular Simulation of Methane Adsorption on Type II Kerogen with the Impact of Water Content. J. Pet. Sci. Eng. 2018, 161, 302-310.

(27) Huang, L.; Ning, Z.; Wang, Q.; Zhang, W.; Cheng, Z.; Wu, X.; Qin, H. Effect of Organic Type and Moisture on $\mathrm{CO}_{2} / \mathrm{CH}_{4}$ Competitive Adsorption in Kerogen with Implications for $\mathrm{CO}_{2}$ Sequestration and Enhanced $\mathrm{CH}_{4}$ Recovery. Appl. Energy 2018, $210,28-43$.

(28) Huang, L.; Ning, Z.; Wang, Q.; Qi, R.; Zeng, Y.; Qin, H.; Ye, H.; Zhang, W. Molecular Simulation of Adsorption Behaviors of Methane, Carbon Dioxide and Their Mixtures on Kerogen: Effect of Kerogen Maturity and Moisture Content. Fuel 2018, 211, 159-172.

(29) Khan, N. A.; Engle, M.; Dungan, B.; Holguin, F. O.; Xu, P.; Carroll, K. C. Volatile-Organic Molecular Characterization of ShaleOil Produced Water from the Permian Basin. Chemosphere 2016, 148, 126-136.

(30) Shrestha, N.; Chilkoor, G.; Wilder, J.; Gadhamshetty, V.; Stone, J. J. Potential Water Resource Impacts of Hydraulic Fracturing from Unconventional Oil Production in the Bakken Shale. Water Res. 2017, $108,1-24$.

(31) An, B. A.; Shen, Y.; Voordouw, G. Control of Sulfide Production in High Salinity Bakken Shale Oil Reservoirs by Halophilic Bacteria Reducing Nitrate to Nitrite. Front. Microbiol. 2017, 8, 1164.

(32) White, D. E. Saline Waters of Sedimentary Rocks. Am. Assoc. Pet. Geol. Mem. 1965, 4, 342-365.

(33) McCarthy, K.; Rojas, K.; Niemann, M.; Palmowski, D.; Peters, K.; Stankiewicz, A. Basic Petroleum Geochemistry for Source Rock Evaluation. Oilfield Rev. 2011, 23 (2), 32-43.

(34) Philp, R. P. Petroleum Formation and Occurrence. Eos Trans. AGU 1985, 66 (37), 643-644.

(35) Ungerer, P.; Collell, J.; Yiannourakou, M. Molecular Modeling of the Volumetric and Thermodynamic Properties of Kerogen: Influence of Organic Type and Maturity. Energy Fuels 2015, 29 (1), 91-105.

(36) Kelemen, S. R.; Afeworki, M.; Gorbaty, M. L.; Sansone, M.; Kwiatek, P. J.; Walters, C. C.; Freund, H.; Siskin, M.; Bence, A. E.; Curry, D. J.; Solum, M.; Pugmire, R. J.; Vandenbroucke, M.; Leblond, M.; Behar, F. Direct Characterization of Kerogen by X-Ray and SolidState ${ }^{13} \mathrm{C}$ Nuclear Magnetic Resonance Methods. Energy Fuels 2007, 21 (3), 1548-1561.

(37) Mayo, S. L.; Olafson, B. D.; Goddard, W. A. DREIDING: A Generic Force Field for Molecular Simulations. J. Phys. Chem. 1990, 94 (26), 8897-8909.

(38) Zhou, B.; Xu, R.; Jiang, P. Novel Molecular Simulation Process Design of Adsorption in Realistic Shale Kerogen Spherical Pores. Fuel 2016, 180, 718-726.

(39) Collell, J.; Ungerer, P.; Galliero, G.; Yiannourakou, M.; Montel, F.; Pujol, M. Molecular Simulation of Bulk Organic Matter in Type II Shales in the Middle of the Oil Formation Window. Energy Fuels 2014, 28 (12), 7457-7466.

(40) Martin, M. G.; Siepmann, J. I. Transferable Potentials for Phase Equilibria. 1. United-Atom Description of n-Alkanes. J. Phys. Chem. B 1998, 102 (14), 2569-2577.

(41) Grigera, J.; Berendsen, H. J. C.; Straatsma, T. P. The Missing Term in Effective Pair Potentials. J. Phys. Chem. 1987, 91 (24), 62696271.

(42) Cygan, R. T.; Liang, J.-J.; Kalinichev, A. G. Molecular Models of Hydroxide, Oxyhydroxide, and Clay Phases and the Development of a General Force Field. J. Phys. Chem. B 2004, 108 (4), 1255-1266.

(43) Talu, O.; Myers, A. L. Reference Potentials for Adsorption of Helium, Argon, Methane, and Krypton in High-Silica Zeolites. Colloids Surf., A 2001, 187-188, 83-93.

(44) Lorentz, H. A. Ueber Die Anwendung Des Satzes Vom Virial in Der Kinetischen Theorie Der Gase. Ann. Phys. 1881, 248 (1), 127136.

(45) Lemmon, E.; McLinden, M.; Huber, M. NIST Standard Reference Database 23: Reference Fluid Thermodynamic and Transport
Properties-REFPROP, Version 9.1; National Institute of Standards and Technology (NIST): Gaithersburg, MD, 2013.

(46) Jorgensen, W. L.; Madura, J. D.; Swenson, C. J. Optimized Intermolecular Potential Functions for Liquid Hydrocarbons. J. Am. Chem. Soc. 1984, 106 (22), 6638-6646.

(47) Pekka, M.; Lennart, N. Structure and Dynamics of the TIP3P, SPC, and SPC/E Water Models at 298 K. J. Phys. Chem. A 2001, 105, 9954-9960.

(48) Plimpton, S. Fast Parallel Algorithms for Short-Range Molecular-Dynamics. J. Comput. Phys. 1995, 117 (1), 1-19.

(49) Hoover, W. G. Canonical Dynamics: Equilibrium Phase-Space Distributions. Phys. Rev. A: At., Mol., Opt. Phys. 1985, 31, 1695-1697.

(50) Hoover, W. G. Constant-Pressure Equations of Motion. Phys. Rev. A: At., Mol., Opt. Phys. 1986, 34 (3), 2499-2500.

(51) Frenkel, D.; Smit, B. Understanding Molecular Simulation: From Algorithms to Applications, 2nd ed.; Academic Press: San Diego, CA, 2002; DOI: 10.1016/B978-0-12-267351-1.X5000-7.

(52) Tian, Y.; Yan, C.; Jin, Z. Characterization of Methane Excess and Absolute Adsorption in Various Clay Nanopores from Molecular Simulation. Sci. Rep. 2017, 7 (1), 1-21.

(53) Brandani, S.; Mangano, E.; Sarkisov, L. Net, Excess and Absolute Adsorption and Adsorption of Helium. Adsorption 2016, 22 (2), 261-276.

(54) Okiongbo, K. S.; Aplin, A. C.; Larter, S. R. Changes in Type II Kerogen Density as a Function of Maturity: Evidence from the Kimmeridge Clay Formation. Energy Fuels 2005, 19 (6), 2495-2499.

(55) Gasparik, M.; Ghanizadeh, A.; Bertier, P.; Gensterblum, Y.; Bouw, S.; Krooss, B. M. High-Pressure Methane Sorption Isotherms of Black Shales from the Netherlands. Energy Fuels 2012, 26 (8), 4995-5004.

(56) Rexer, T. F.; Mathia, E. J.; Aplin, A. C.; Thomas, K. M. HighPressure Methane Adsorption and Characterization of Pores in Posidonia Shales and Isolated Kerogens. Energy Fuels 2014, 28 (5), 2886-2901.

(57) Li, J.; Zhou, S.; Gaus, G.; Li, Y.; Ma, Y.; Chen, K.; Zhang, Y. International Journal of Coal Geology Characterization of Methane Adsorption on Shale and Isolated Kerogen from the Sichuan Basin under Pressure up to $60 \mathrm{MPa}$ : Experimental Results and Geological Implications. Int. J. Coal Geol. 2018, 189, 83-93.

(58) Czepirski, L.; Balys, M. R.; Komorowska-Czepirska, E. Some Generalization of Langmuir Adsorption Isotherm. J. Chem. 2000, 3 (14), 1099-8292.

(59) Langmuir, I. Adsorption of Gases on Plain Surfaces of Glass Mica Platinum. J. Am. Chem. Soc. 1918, 40 (9), 1361-1403.

(60) Kim, J.; Kim, D.; Lee, W.; Lee, Y.; Kim, H. Impact of Total Organic Carbon and Specific Surface Area on the Adsorption Capacity in Horn River Shale. J. Pet. Sci. Eng. 2017, 149 (May), $331-339$

(61) Xia, X.; Tang, Y. Isotope Fractionation of Methane during Natural Gas Flow with Coupled Diffusion and Adsorption/ Desorption. Geochim. Cosmochim. Acta 2012, 77, 489-503.

(62) Zou, J.; Rezaee, R.; Liu, K. Effect of Temperature on Methane Adsorption in Shale Gas Reservoirs. Energy Fuels 2017, 31 (11), 12081-12092.

(63) Graziano, G. Salting out of Methane by Sodium Chloride: A Scaled Particle Theory Study. J. Chem. Phys. 2008, 129 (8), 084506.

(64) Yamamoto, S.; Alcauskas, J. B.; Crozier, T. E. J. Chem. Eng. Data 1976, 21 (1), 78-80.

(65) Ben-Naim, A.; Yaacobi, M. Effects of Solutes on the Strength of Hydrophobic Interaction and Its Temperature Dependence. J. Phys. Chem. 1974, 78 (2), 170-175. 